Capítulo 4

\title{
Pionera: los aportes de Michèle Mattelart al campo comunicacional
}

DOI: https://doi.org/10.16.921/ciespal.23.24

Yamila Heram

Universidad de Buenos Aires, Argentina

Santiago Gándara

Universidad de Buenos Aires, Universidad de La Pampa, Argentina

\section{Resumen}

En los balances y retrospectivas del campo comunicacional latinoamericano las obras más nombradas refieren a los padres fundadores. Esto advierte de un hecho evidente, los aportes de las mujeres ocupan un lugar periférico. Si bien Michèle Mattelaert ha sido una de las pioneras que, en este contexto desigual, más reconocimiento ha obtenido, y sin desconocer que la trayectoria de Michèle y Armand ha sido en gran parte compartida y de mutua influencia y diálogo, este artículo se centra en caracterizar el recorrido intelectual de Michèle y detenernos específicamente en una lectura de los trabajos de su primera etapa (1963-1973), es decir aquellos escritos que han marcado sus aportes pioneros al campo comunicacional latinoamericano.

Palabras clave: campo comunicacional - Michèle Mattelart - mujeres pioneras - latinoamérica 


\begin{abstract}
:
In the balance sheets and retrospectives of the latin american communication field, the most named works refer to the founding fathers. This warns of an evident fact, the contributions of women occupy a peripheral place. Although Michèle Mattelaert has been one of the pioneers who, in this unequal context, has received the most recognition, and without ignoring that Michèle and Armand's trajectory has been largely shared and of mutual influence and dialogue, this article focuses on characterize Michèle's intellectual journey and stop specifically at a reading of the works of her first stage (1963-1973), that is, those writings that have marked her pioneering contributions to the latin american communication field.
\end{abstract}

Key Words: communication field - Michèle Mattelart - pioneering women - latin american.

\title{
Introducción
}

En los balances y retrospectivas del campo de la comunicación en América Latina podemos ubicar un amplio abanico de investigaciones que se han ceñido a balances de una trayectoria personal de investigación de los referentes del campo latinoamericano, los llamados "padres fundadores": Luís Ramiro Beltrán, Armand Mattelart, Jesús Martín Barbero, Eliseo Verón, Héctor Schmucler, Antonio Pasquali, José Marques de Melo, Rafael Rocangolio, Mario Kaplún, Eleazar Díaz Rangel, entre otros (Castro, 2008; Sánchez Narvate, 2019; Michel Sénécal, 2010; Esteinou Madrid, 2002; Zarowsky, 2013, 2016; Aguirre Alvis, 1997; Rincón (eds.) 2018; Marroquín, 2015; Solís Leree y Kaplún, 2015; entre otros). No hay madres, para seguir con la analogía de la familia. Esto nos advierte de un hecho tan evidente como invisible: los aportes de las mujeres al campo de la comunicación en América Latina -y podríamos hacerlo 
más extensivo a la geografía internacional- en general ocupan un lugar periférico: sus nombres, sus trayectorias y sus obras.

En los últimos tiempos la temática en torno a las mujeres está ocupando gran parte de la agenda de los medios y del interés público. Para ello, las mujeres debieron abrir intensos debates, desarrollar sus propios colectivos de organización y desplegar masivas movilizaciones, enfrentar a los poderes. Sin embargo, no solo persisten las dificultades -esto es, las desigualdades- que continúan sin resolverse sino que, en relación con nuestro tema, se mantiene el desconocimiento -lo opuesto al reconocimiento- de una serie de investigadoras que fueron pioneras de los estudios de comunicación en América Latina. Si bien Michèle Mattelart ha sido una de las pioneras en comunicación que, en este contexto desigual, más reconocimiento ha obtenido, este artículo tiene por objetivo centrarnos en sus trabajos. Sin desconocer que la trayectoria intelectual de Michèle y Armand ha sido en gran parte compartida y que la mutua influencia y diálogo es parte de esa trayectoria personal y política, nos interesa especialmente detenernos en la de Michèle, para así poder trazar un recorrido por sus trabajos y rescatar los aportes de la autora a los estudios de comunicación latinoamericanos.

En ese sentido el trabajo que presentamos se inscribe en una serie mayor ${ }^{1}$ que tiene por objetivo visibilizar a las mujeres pioneras del campo comunicacional latinoamericano. Por solo nombrar algunas de las autoras, podemos destacar por su labor desde la perspectiva de la economía política de la comunicación o como se la llamaba en los años '70 la "sociopolítica de las comunicaciones" a Elizabeth Fox, Nelly de Camargo, Margarita Graziano y Fátima Fernández Christieb, entre otras. Desde el análisis crítico de discurso los trabajos de Michèle Mattelart, Mabel Piccini, Beatriz Sarlo, Paula Wajsman, Silvia Molina y Vedia y Lisa Block de Behar, entre otras. En un área aún menos explorada en esa época también cabe mencionar el trabajo de Regina Gibaja y los de Michèle Mattelart y Mabel Piccini sobre consumo y recepción.

1 Por motivos de anonimato no se escriben los datos del proyecto de investigación. 
Muchos de estos escritos han sido publicados en revistas emblemáticas de la época, hacemos referencia a Comunicación y Cultura, LENGUAjes, Chasqui, ININCO y Los Libros, además de la edición de libros. Con trayectorias disímiles e itinerarios que en algunas ocasiones se han desplazado hacia otros intereses, estas autoras (entre otras) han publicado, debatido y formado parte de organismos estatales y sociales trabajando desde la comunicación para un cambio social.

Aquí presentamos los aportes de Michèle Mattelart y una lectura de sus trabajos a lo largo de su trayectoria, haciendo especial foco en sus primeros años. El artículo está organizado en dos apartados, en el primero damos cuenta brevemente de sus obras y establecemos tres etapas en el itinerario intelectual de la autora. En el segundo apartado nos detenemos especialmente en una lectura de los trabajos de su primera etapa (19631973), es decir aquellos escritos que han marcado sus aportes pioneros al incipiente campo comunicacional. Para ello elegimos tres ejes que organizan sus temas, su campo de problemas y sus principales respuestas: el cambio social, la cuestión de la mujer y la recepción.

\section{Etapas}

La vasta producción de Michèle Mattelart a lo largo de su carrera nos permite trazar diferentes etapas de su itinerario intelectual. Ha escrito decenas de artículos y libros -especialmente en español, francés e inglés- de manera colectiva e individual, muchos de ellos con Armand Mattelart, otros que aquí también trabajaremos junto con Mabel Piccini. Tras una lectura exhaustiva de sus trabajos, seleccionamos, a los fines analíticos, algunos de los más representativos. Distinguimos tres etapas en su itinerario intelectual, la primera la situamos desde su llegada a Chile en 1963 hasta el golpe de estado efectuado por Pinochet en septiembre de 1973, caracterizada por su praxis intelectual y política. Una segunda etapa que va desde el golpe de estado en 1973 a mediados de los años ochenta que será de transición y balance de aquella 
experiencia intelectual y política. Por último, una tercera etapa desde mediados de los ochenta hasta la actualidad que será de consolidación y de reconocimiento extendido también en el campo de los estudios feministas en comunicación.

La primera etapa la situamos desde la llegada de Michèle Mattelart (nacida en Francia en 1941) a Chile en 1963 hasta el golpe de estado de 1973. Arriba al país junto con Armand, con quien acababa de contraer matrimonio y quien había viajado un año antes para asumir un puesto en la Escuela de Sociología de la Pontificia Universidad Católica de Chile. Recién diplomada en Literatura Comparada en la Sorbona, enseña en la Alianza Francesa, dicta clases de literatura francesa en el Instituto Pedagógico de la Universidad Católica de Chile e inaugura junto con Mabel Piccini y Armand Mattelart, a fines de 1967, un grupo de investigación sobre la ideología, la cultura y la cultura de masas, en el Centro de Estudios de la Realidad Nacional (CEREN), dependiente de la Pontificia Universidad Católica (PUC). Tras la asunción del gobierno de la Unidad Popular, forma parte del equipo de Onda, un fanzine juvenil editado por la nacionalizada editorial Quimantú, y trabaja en el departamento de guiones en la televisión nacional. El golpe de estado de Pinochet en septiembre de 1973 la encuentra en Cuba, donde dictaba un seminario en la Universidad de La Habana.

En esa década descubre un problema casi inexplorado en el incipiente campo comunicacional: la relación mujer/medios, como resultado no solo de sus tempranas lecturas: Roland Barthes y Algirdas Greimas (el estructuralismo francés), Theodor Adorno y Herbert Marcuse (Escuela de Frankfurt), Edgar Morin y hasta los escritos de Alejandra Kollontai, sino fundamentalmente de su experiencia en el proceso chileno.

Reconozco que buena parte de los avances en el plano teórico que tuvieron influencia en la aproximación al tema 'Mujer/ Medios', se los debo a la historia social y política de este país y, particularmente, a mi participación activa en un período clave de su historia, a mi compromiso al lado de los sectores que impulsaron un cambio democrático. (Mattelart, 2014, p. 2). 
De esta época consignamos uno de sus primeros trabajos en colaboración con Armand Mattelart: La mujer chilena en una nueva sociedad (1968), donde encaran un estudio exploratorio de la actitud de las mujeres chilenas, en diferentes sectores sociales, frente al denominado "cambio social". Indagan sobre sus concepciones en torno a la familia y el control de la natalidad, así como sobre el uso de los medios de comunicación.

En ese libro anudan una línea de investigación sobre cambio social, mujer y medios, que Michèle Mattelart desarrollaría de manera sistemática en su trabajo sobre la fotonovela (El nivel mítico de la prensa seudo-amorosa, 1970) y sobre los semanarios ilustrados (Apuntes sobre lo moderno: una manera de leer el magazine, 1971). También integramos en esta primera serie el artículo sobre los consumos televisivos en las poblaciones de Santiago de Chile, resultado de una investigación realizada junto con la argentina Mabel Piccini en 1972 y publicada tras el golpe en la revista Comunicación y Cultura "La televisión y los sectores populares" (1974). También sumamos La prensa burguesa, ¿̇no será más que un tigre de papel? Los medios de comunicación de la oposición durante la crisis de octubre de 1972 (1973), escrito junto con Mabel Piccini, allí analizan el papel que cumplieron los medios chilenos (diario El Mercurio, pero también las radios y la televisión) como "plataforma privilegiada de lanzamiento de la ofensiva burguesa" (p. 250) a partir de un acontecimiento: el paro patronal de la confederación de camioneros, al que se sumarían amplios sectores de la pequeña burguesía, durante el mes de octubre de 1972, continuando una línea abierta en el mes de diciembre de 1971 con las marchas de las cacerolas.

La segunda etapa la situamos desde el golpe miliar en 1973 hasta mediados de los años ochenta, será de balance y transición de aquella experiencia intelectual y política. Sin considerar la obra en co-autoría, destacamos tres trabajos: Cuando las mujeres de la burguesía salen a la calle (1975), publicado por primera vez en versión inglesa para North American Congress on Latin America (NACLA) y en francés en Les Temps Modernes, donde examina la instrumentación de valores femeninos y el 
papel asignado a las mujeres burguesas en la construcción del consenso para el golpe de estado; el libro La cultura de la opresión femenina (1977), que reúne-y eso expresa un primer balance sobre su propia trayectoria chilena- este último trabajo y los ya publicados sobre los semanarios ilustrados y las fotonovelas; Mujeres e industrias culturales (1982), producto de una investigación, publicada un año antes como folleto por la Organización de las Naciones Unidas para la Educación, la Ciencia y la Cultura (UNESCO), donde tal vez se presente su obra más madura, en la que convergen las perspectivas de la economía política, del análisis del discurso de orientación francesa y los estudios de género.

Por último, una tercera etapa que va desde mediados de los ochenta hasta la actualidad, que será de consolidación y de reconocimiento extendido también en el campo de los estudios feministas en comunicación. De sus diversas publicaciones de esta etapa seleccionamos, por un lado, Pensar sobre los medios (1986). Se trata de un texto clave en el que Armand y Michèle Mattelart repasan críticamente las principales corrientes teóricas que asomaron en la década de los ochenta (relecturas de Antonio Gramsci, Michel Foucault, Michel de Certeau, los Cultural Studies) y que confluyen en un nuevo paradigma comunicacional: de lo mecánico a lo fluido, en el cuadro de un proceso mayor de reorganización social del capital. A diferencia de otras obras entonces contemporáneas, los autores reconocen los cambios teóricos pero, al mismo tiempo, reclaman la persistencia de los viejos marcos de análisis, en particular del marxismo.

El otro libro, también escrito en conjunto, es El carnaval de las imágenes. La ficción brasileña (1987), resultado de investigaciones sobre la serialización televisiva que Michèle Mattelart venía desarrollando en el marco de la Centre National de la Recherche Scientifique (CNRS). Sobre este último, Armand Mattelart escribe:

Este libro hace juego con Pensar sobre los medios. Cuestiones teóricas que se desarrollan en este último, toman una forma práctica en El carnaval de las imágenes. Es el caso de la interrogación sobre conceptos tales como 
dispositivo, cultura popular, hegemonía, intelectual orgánico, disciplina y antidisciplina, etc. (Mattelart, 2013, p. 161).

Finalmente, sumamos en este último período, su libro Women, Media, Crisis: Feminity and Disorder (1986) -entre tantos otros artículo que siguió publicando en revistas científicas- que recoge sus anteriores contribuciones cuando todavía no se hablaba de la relación género/ medios y que comienza a colocar a Michèle Mattelart como pionera en los estudios de género y -no sin reservas de su parte- en el campo de los Women Study. También cabe mencionar que de las mujeres pioneras en los estudios de comunicación, Michèle Mattelart, quizá sea una de las más reconocidas por sus aportes, entre los premios y homenajes recibidos en las diferentes latitudes podemos destacar: Doctorado Honoris Causa junto con Armand por la Universidad de Málaga (2014, España) y la Universidad de Valladolid (2016, España), homenaje en la IX Bienal Iberoamericana de Comunicación (Chile) -junto con Armand- (2013), homenaje por la Unión Latina de la Economía Política de la Información, la Comunicación y la Cultura (ULEPICC) en el XI Congreso de esta asociación científica internacional (2019), entre otros tantos.

\section{Una lectura de sus primeros trabajos}

En lo que sigue expondremos los aportes pioneros de Michèle Mattelart durante el período chileno (1963-1973), que se corresponde con la etapa de autonomización del campo de la comunicación en América Latina en términos de Raúl Fuentes Navarro (1992), fundacional siguiendo a Delia Crovi Druetta (2004), o pionero en palabras de José Marques de Melo. No incluimos en estas consideraciones a las publicaciones que realizara en conjunto con Armand Mattelart, porque estas últimas -si bien subsumidas en la trayectoria y la obra de Armand- han sido abordadas en contadas oportunidades en publicaciones y libros ${ }^{2}$. No podemos dejar de señalar que escindir esas obras "escritas a cuatro manos"

2 Esteinou Madrid, (2002); Michel Sénécal, (2014); Zarowsky, (2013); entre otros. 
es una tarea imposible (cómo delimitar los aportes de una y otro, y para qué), pero sobre todo es arbitraria: desde su primer estudio sobre la mujer chilena hasta Historia de las teorías de la comunicación (1997), los trabajos de Armand y Michèle Mattelart revelan no solo experiencias comunes (personales, desde ya, pero también políticas) y perspectivas compartidas sino una larga conversación y una sostenida polémica intelectual en torno a los problemas de la comunicación a lo largo de las últimas seis décadas, en Chile, en las breves estadías de Mozambique o Nicaragua, y en Francia.

Con todo, un examen sobre los trabajos de Michèle Mattelart nos permite echar luz sobre sus contribuciones personales y su propio lugar en la tradición de los estudios latinoamericanos de comunicación. Elegimos tres ejes para organizar sus temas, su campo de problemas y sus principales respuestas: el cambio social, la cuestión de la mujer y la recepción.

\section{Cambio social}

La idea de "cambio social" ocupaba el centro del debate y de la lucha política en Chile y en América Latina. Desde la perspectiva del imperialismo estadounidense, el "cambio" era equivalente al necesario proceso de modernización capitalista que debían atravesar los países de América Latina y, más extensamente, del entonces llamado Tercer Mundo. Como si se tratara de un movimiento ineluctable (y así lo expresaba, por caso, la teoría de las etapas de Rostow), las sociedades tradicionales deberían pasar sucesivas etapas de desarrollo y transición hasta alcanzar el grado más alto civilizatorio: la sociedad del consumo masivo. La circulación de esta teoría y las concepciones "desarrollistas" de la comunicación ${ }^{3}$ sintonizaban con el programa de la Alianza para el Progreso, que el gobierno estadounidense había promocionado en 1961 como supuesta ayuda económica, política y social -que se revelaría un

3 Un representante de esta corriente fue Wilbur Schramm, que publica Desarrollo de la Comunicación y Desarrollo Económico, en 1965, y que encuentra su fundamento en la teoría de Rostow, muy difundida y promovida por los Estados Unidos en la década del sesenta. 
fracaso y un fraude, al mismo tiempo- para contrarrestar los efectos de la revolución cubana y los procesos de ascenso de lucha de masas en la región. Este paquete de ideas modernizadoras encontraba un canal privilegiado de difusión en los medios de prensa, las revistas, la radio y la televisión.

Contra esa ideología modernizadora se levantaron otros planteos: la falta de desarrollo en los países de América Latina era el producto no de la ausencia de procesos de modernización sino de la relación dependiente, desigual, entre los países centrales y periféricos. Aquí se amalgaman la Teoría de la Dependencia ${ }^{4}$, las concepciones pedagógicas y comunicacionales de Paulo Freire (quien también se refugió en Chile), la teoría leninista del imperialismo y el marxismo. Aquí, el concepto de "cambio" se tensionaba entre la reforma (de la cual la experiencia chilena sería su dramático laboratorio) y la revolución (la experiencia cubana, como el otro polo).

En ese campo de problemas, que reconstruimos apretadamente, Michèle Mattelart desarrolla sus primeras investigaciones sobre las fotonovelas y sobre los semanarios femeninos.

Interrogarse sobre el concepto de modernidad que se instituye, a modo de égida, en el santo y seña de la producción de bienes y de signos de la sociedad industrial capitalista constituye, tal vez, una de las maneras valederas de acercarse al principio rector de un sistema de dominación social que se absuelve de su dinamismo y justifica su noción de progreso repitiendo a diario, y hasta la saciedad, la carta magna del mejoramiento creciente del environment, del consumo abierto y de la felicidad tecnológica. (1971, p. 29).

Para Michèle Mattelart, la modernidad y sus promesas de bienestar se han constituido en la ideología del nuevo imperialismo y de una nueva burguesía. En ese sentido, los medios masivos, que se definen

4 Tras el golpe de Estado en Brasil, en 1964, varios de los intelectuales que contribuyeron a la elaboración de la Teoría de la Dependencia emigraron a Chile -Theotonio dos Santos, Ruy Mauro Marini, entre otrosdonde establecieron nuevas redes intelectuales. 
"por las necesidades de un sistema de poder", devienen en instituciones, que producen y ponen en circulación tales discursos (sobre lo moderno, la moda, el mundo de hoy, el último grito, la novedad) que no son más que una "morfología, que rehabilita un contenido permanente, idéntico, y una normativa que apunta siempre a privilegiar el conformismo" (Michèle Mattelart, 1971, p. 43).

En La prensa burguesa, ¿no será más que un tigre de papel? Los medios de comunicación de la oposición durante la crisis de octubre de 1972 (1973), escrito junto con Mabel Piccini, la tesis central del texto es que, en los momentos de crisis o de agudización de la lucha de clases, los medios abandonan sus principios: objetividad, transparencia informativa, independencia de los poderes, representación de la opinión pública. La crisis hace estallar estas mistificaciones.

Cuando las clases dominantes no están impugnadas en sus intereses, se programa un vacío entre información y acción y es sobre este vacío que opera la prensa burguesa, cuyo objetivo básico es entonces la desorganización de las masas. Ella habla al hombre individual, al individuo segregado de su clase, a la opinión pública concebida como suma de conciencias aisladas, que es la que respalda tácitamente su sistema de dominación. Cuando es acometida en sus intereses, la burguesía necesita movilizar concretamente a la opinión en torno a la defensa de su proyecto de clase (p. 253).

De allí que identifiquen una "línea de masas" (p. 256) de los medios burgueses que se expresa en la conformación de un liderazgo político, en la "practicidad de los mensajes puestos en circulación" (p. 252), en la interpelación a los destinatarios inorgánicos para organizarlos en

5 Esta idea de "línea de masas" es compartida también por Armand Mattelart: "Las alteraciones que la burguesía hizo sufrir a su modelo de comunicación con sus clientelas dependen, en última instancia, de sus alternativas políticas. Aquí, para ilustrar la movilidad del enemigo de clase en la batalla ideológica, trataremos de mostrar cómo la alternativa que eligió la línea de masas y su órgano periodístico principal, El Mercurio, armó progresivamente a su público para desembocar en octubre de 1972 en la explosión del poder gremialista y encauzar su acción sediciosa (1973, p. 213-241). 
torno al programa de la burguesía y del imperialismo, en la persistencia de ciertos tópicos contra el gobierno de la UP (descalabro económico, ruptura convivencia democrática y amenaza a la libertad de expresión), en definitiva, en su conversión a medios de agitación, propaganda y organización colectiva pero de un frente contrarrevolucionario.

\section{Mujeres}

Ahora bien, ¿cómo conectan estas problemáticas de la ideología modernizadora y los medios con las mujeres? En un trabajo posterior, Michèle Mattelart va a sostener que esa correlación se explica porque la mujer está destinada, en virtud de una combinación de mecanismos ideológicos y culturales, a cumplir "una función reguladora" en la sociedad y a ser "el eje del consumo y agente determinante de la socialización de los niños, la encargada de transmitir los códigos de autoridad, de hacer asimilar las imágenes y los papeles masculinos y femeninos discriminados" (1982, p. 7). Por eso, las mujeres -señala la autora- están en el centro de una estrategia de acción de los medios. En ese sentido, el análisis de las fotonovelas y de los seminarios ilustrados se revela como un camino privilegiado para abordar un sistema de significaciones, de estereotipos, de operaciones ideológicas o mitificadoras.

En El nivel mítico de la prensa seudo-amorosa (1970) aborda un corpus de Cine Amor, una fotonovela semanal chilena fundada en 1960, destinada y consumida particularmente por las mujeres de los sectores populares. A partir del modelo barthesiano de Mitologías, Mattelart va a identificar el eje organizador de estos materiales masivos: el orden del corazón, un principio que "confiere a la idiosincrasia fotonovelesca una coherencia irreprochable” (p. 261) al que se suman como ayudantes: la naturaleza y el destino. A partir de allí, al examinar estereotipos y recurrencias, advertirá lo nuevo como reiteración (cada fotonovela anuncia una novedad, pero repite sus temas, su elenco de estrellas, sus clisé), el rechazo al mundo material (salvo en los rubros publicitarios, se elude todo lo que podría recordar la actividad social y económica, o al mundo del trabajo), la dilución de los conflictos (la 
rebeldía juvenil que termina reintegrándose al orden), entre otras figuras mitológicas. Ese mundo encerrado de la fotonovela no impide que:

Llegado el momento, el comadreo del editorial se metamorfosea en una interpretación de la realidad social y en una adscripción de valores, de actitudes y de modos de actuar. El lector semanal no se percata de la ambigüedad de esta mutación preparada y orquestada por una sobrepuja de familiaridad y de efusión doméstica. Bajo fines de diversión y de evasión, la revista de fotonovelas se afana en infiltrar las pretensiones de un mensaje trascendental: la verdad sobre la condición humana. A un arte de entretenerse, corresponde un arte de vivir, un código moral. Veremos cómo esta finalidad que el editorial, al presentársete la oportunidad, deja entrever en la grandilocuencia repentina del tono, es inmanente al discurso fotonovela. (Mattelart, 1970, p. 232).

En Apuntes sobre lo moderno: una manera de leer el magazine (1971), el más republicado y traducido de sus trabajos, aborda los seminarios ilustrados femeninos. Allí identifica procedimientos mitológicos tales como el "universal femenino" (que disuelve las clases), la "eternidad ficticia" (donde lo nuevo se muestra "trivialidad repetitiva"), la "democracia del deseo" (sobre los consumos segregados socialmente), la "democracia de los temas" (donde el sincretismo diluye los asuntos conflictivos que pudieran abordarse), la "deshistorización" (por lo cual la naturaleza se convierte en una referencia valorativa), la "omnipotencia del objeto" (que traslada lo cualitativo del sujeto al objeto), entre otros. Una de sus tesis plantea:

La mujeres, que imagen o realidad, soporta más que el hombre la cotidianidad y que sigue ocupando el centro de esta misma esfera de lo cotidiano, era ciertamente el foco más adecuado desde el cual hacer irradiar la cultura de la modernidad, que difusamente pretende influir en el contexto diario moldeando ambientes, gustos, deseos. (Mattelart, 1971, p. 34).

La serie de estos trabajos continúa en 1975 en lo que caracterizamos como la etapa de transición de la obra de Michèle Mattelart. Nos referimos a Chile: The Feminine When Bourgeois Women Side of the Coup 
or Take to the Streets (su versión castellana aparece bajo el título Cuando las mujeres de la burguesía salen a la calle, en 1977). Se trata de un análisis de los medios masivos, en particular de las revistas femeninas adscriptas a la derecha chilena, en su estrategia contrarrevolucionaria para derrocar a Salvador Allende. Mattelart advierte el uso de la mujer -del estereotipo femenino, del lugar asignado socialmente a la mujeres- que tuvo cada vez mayor protagonismo en las protestas (los cacerolazos) que prepararían las condiciones del golpe de Estado. En otras palabras, aquí Michèle Mattelart ilustra la "línea de masas" que la burguesía chilena va a desplegar desde los medios de comunicación. En un balance posterior, la autora señala:

Estas manifestaciones callejeras revelaron, bajo una forma activa, los valores que los medios de comunicación tradicionales o modernos no habían dejado nunca de cultivar bajo su forma pasiva. Demostraban en medio de la violencia cómo el carácter privado, pasivo, atribuido a lo femenino, que las fotonovelas y las revistas habían acuñado en el discurrir de los días con ensoñaciones sobre aventuras de deseo amoroso o deseo de consumo, podía perder esa aparente inercia dentro de la vida política para convertirse en un arma singularmente importante en las campañas de opinión contra un régimen popular constitucionalmente elegido y sus programas de reforma. Estas mujeres se transformaron en el mejor arma para el combate político, permitiendo dotar de inocencia la subversión, presentándola como la reacción del sector tradicionalmente apolítico de la opinión, preocupado únicamente por asuntos domésticos y maternales: «Es una mujer quien os habla» o mejor «Es una madre quien os habla». (Mattelart, 2007, p. 40).

La preocupación en torno mujeres / medios será un tema recurrente en la trayectoria intelectual de la autora y sobre lo cual recibirá reconocimiento no sólo por sus aportes al campo comunicacional sino también en el campo de debates de las teorías de feministas.

\section{La recepción: clase y género}

Tras un largo epígrafe de Bertolt Brecht sobre el sentido de lo popular -"nos referimos al pueblo que no solo participa de la revolución, 
sino que se apodera de ella, la impone, la condiciona"-, el artículo La televisión y los sectores populares, escrito junto con Mabel Piccini, introduce una cuestión central en el debate político chileno: "el rol que le cabe cumplir al frente cultural en un proceso de agudización de la lucha de clases" (p. 4). Las autoras afirman que para quebrar "un sistema que funda su legitimidad en la manipulación de las conciencias" es necesario desarrollar un proyecto alternativo popular a partir de "un criterio de clase", que se abra realmente "hacia aquellos sectores que producen los cambios".

En otras palabras, el trabajo se inscribe en una polémica hacia el interior de la izquierda, particularmente con los partidos que integran el frente de la Unidad Popular ${ }^{6}$, en relación con sus políticas culturales difusionistas (por caso, la producción de televisores populares a bajo costo, distribuidos a través de las organizaciones populares) que mantienen a las mayorías como "espectadores" y desmovilizan a las "vanguardias populares" que, en forma embrionaria, comenzaban a crear poder popular "tanto en la lucha por la conquista del poder político como en el proceso ininterrumpido de revolucionarización de las prácticas culturales que legitiman el dominio de una clase sobre las demás" (p. 4).

Para la investigación realizaron 200 encuestas entre los sectores populares residentes en cuatro poblaciones del gran Santiago. La elección de las poblaciones se fundamenta, de un modo general, en que se trata de lugares residenciales, que constituyen centros de otro tipo de socialización, disociados de los lugares de trabajo (o de "explotación directa”) y por tanto generadores de niveles de conciencia más

6 Michèle y Armand Mattelart ya habían adelantado un primer balance crítico de las políticas comunicacionales del gobierno e incluso alertado acerca del avance de la contrarrevolución. En Ruptura y continuidad en la Comunicación: puntos para una polémica concluyen: "podemos comprobar que esta problemática de la comunicación masiva es relativamente nueva para los partidos tradicionales y que muchas veces están lejos de poder cumplir con esta formación para una nueva comunicación. [...] detrás del problema de la comunicación surgen interrogantes mucho más amplios, surgen dudas más profundas que abracan todo el ámbito de las transformación superestructural y este último gira esencialmente alrededor de la pregunta: ¿Quién asegurará la vanguardia ideológica, cuál será su contenido y qué relación con las masas mantendrá esta vanguardia? (1972, p. 143). 
conservadores. Más específicamente, para seleccionar cada población se tuvo en cuenta su base social dominante (más o menos proletarizada, con mayor o menor presencia de sectores medios), la organización interna (a través de instituciones burocráticas o modelos asamblearios) y las formas que asumió históricamente la conquista del terreno (cedido por el Estado o producto de una toma), la línea y conducción política: la población Ex- Sumar se describe como hegemonizada por la Democracia Cristiana; las de Victoria y San Gregorio, como disputadas por la Democracia Cristiana pero también por uno de los partidos de Unidad Popular, el Partido Comunista; el campamento Nueva La Habana con mayor intervención por parte del Movimiento de Izquierda Revolucionario.

A partir de estos criterios, las autoras construyen una matriz de tres modelos en relación con el modo en que cada una de estas poblaciones asume "el problema de la reivindicación cultural", esto es, la lucha de los sectores populares por conquistar el acceso al conocimiento, entretenimiento e información, a saber: a) aceptación y reproducción del orden vigente (la población de Ex-Sumar), b) el desarrollo de reivindicaciones secundarias contra el sistema (La Victoria y San Gregorio) y c) el cuestionamiento radical (el campamento Nueva La Habana). El objetivo del trabajo, entonces, consistía en "medir los distintos grados de cuestionamiento que suscita la práctica televisiva actual a partir de la experiencia concreta y los intereses específicos de la clase obrera" (p. 10).

El paso siguiente es la exploración de los públicos obreros: el lugar que ocupa la televisión en su vida cotidiana, los tipos de consumos (de prensa gráfica, radio, televisión) discriminados por género y entre los sectores poblacionales más o menos movilizados, los modos de recepción colectiva de televisión (ante un parque de receptores escaso), la mayor o menor influencia ideológica, las representaciones en torno a los efectos positivos o negativos de la televisión.

Los dos apartados siguientes sistematizan, a partir de los testimonios recabados, las "nuevas demandas" para una política alternativa 
de clase en los medios de comunicación. En contra de los estudios de teleaudiencia que universalizan y homogenizan al público, las autoras postulan una indagación que considera los esquemas interpretativos, las formas de desciframiento, los códigos de clase que utilizan en el momento de la recepción. De allí que recojan testimonios que, en los sectores más movilizados y críticos, cuestionan el carácter extranjerizante de la programación, la distancia entre los programas y los intereses de la clase obrera, la inexistencia de nuevos valores generados por el proceso de cambio. Finalmente, se interpretan los testimonios en relación con los consumos de teleseries (de amor y policiales y aventura) y los programas de formato político.

En perspectiva, el trabajo de Mattelart y Piccini fue una bisagra en el campo de la investigación latinoamericana en los años setenta. En primer lugar, porque abordan los fenómenos mediáticos desde la recepción, aunque sin dejar de examinar los procesos de producción ya sea en clave de economía política o de análisis ideológico. En segundo lugar, porque, si bien subrayan la naturaleza mitificadora de la televisión, advierten que los procesos de recepción presentan mayores complejidades de las que se pueden derivar de un modelo comunicacional monolítico, pensado solo desde la dominación. Finalmente, porque logran establecer co-relaciones tanto entre formas de recepción y una mayor o menor formación y movilización política de las audiencias, como entre las audiencias y los géneros televisivos de entretenimiento e informativos.

En Mujeres y medios. Memorias de un pensamiento crítico (2007), Michèle Mattelart agrega la siguiente valoración:

Pero lo que resulta turbador es el placer que continuaban procurando esos programas a espectadoras que tenían una percepción crítica de su función alienante y reparaban en los mecanismos a través de los cuales ésta operaba. La cuestión que se planteaba era pues la siguiente: ¿cómo aprehender de una manera más justa y más compleja desde el punto de vista del público ese género televisivo que parecía responder a sus expectativas y conformar en parte una cultura popular femenina? Descubrí la necesidad de profundizar 
en la cuestión del placer experimentado por el público. Curiosamente, en el mismo momento en otros lugares, en contextos muy diferentes, otras investigadoras la descubrieron también, como veremos a continuación. Y estas convergencias, en un momento dado, se revelaron significativas en la evolución de las teorías críticas de los medios de comunicación y de su acercamiento a las culturas populares (p. 41).

Esta consideración retrospectiva pareciera reubicar el trabajo en otra serie: la de los estudios culturales, en la línea de Watching Dallas: Soap Opera and the Melodramatic Imagination (1982), de Ien Ang. Sin embargo, el pionero trabajo de Mattelart y Piccini presenta diferencias notables: la exposición de las encuestas se encuadra en la perspectiva de la economía política, la teoría crítica y una demografía de audiencias, a partir del registro de las condiciones históricas de recepción y de la lucha de clases. De hecho, en ese mismo artículo, Mattelart asume como propias las reflexiones de diversas investigadoras que cuestionan el retorno a la audiencia en la medida en que suelen estudiar la cultura de masas como si ya no representara problema alguno (según la estadounidense Tania Modleski) o en que enfatizan el empoderamiento de las mujeres para desarrollar una imagen de mayor autonomía antes que para cambiar el mundo (la australiana Mary Ellen Brown). En esa misma orientación, y reivindicando la tradición de los estudios latinoamericanos de comunicación, Michèle Mattelart postula la necesidad de profundizar estas cuestiones pero a partir del "encuentro entre economía y cultura".

\section{Conclusiones}

A lo largo de estas páginas hemos trazado un recorrido sobre la trayectoria de Michèle Mattelart. Nos interesó rescatar los aportes de la autora en un campo comunicacional en el que los principales balances y memorias sobre itinerarios y trayectorias intelectuales hacen foco en los llamados "padres fundadores", ello tiene como contracara el lugar 
periféricos que tienen los aportes de las mujeres pioneras del campo comunicacional latinoamericano.

En el artículo nos detuvimos en primer lugar en la caracterización de tres etapas de su trayectoria. La primera la ubicamos desde su llegada a Chile en 1963 hasta el golpe de estado en septiembre de 1973, caracterizada por su praxis intelectual y política. Un segundo momento que recorre desde el golpe de estado hasta mediados de los años ochenta, será de transición y balance de dicha experiencia intelectual y política. Una tercera etapa, desde mediados de los ochenta hasta la actualidad, de consolidación y de reconocimiento.

En una segunda parte del trabajo nos acercarnos a la obra de Michèle en tanto pionera -es decir en la primera etapa (1963 - 1973)- ello implicó poner en una serie histórica y social dichos aportes en relación con las características del campo comunicacional latinoamericano en su período de autonomización, es decir durante sus inicios, con sus problemáticas y sus objetos de estudio. Como se mencionó, el contexto estuvo fuertemente marcado por una serie de cambios políticos, sociales, culturales, debates y luchas políticas que recorren en América Latina el arco que va desde la Revolución Cubana (1959) a las diferentes dictaduras militares que cierran este primer período en la década de 1970.

En la lectura general y de reconstrucción de sus aportes pioneros encontramos una serie de conceptos que se reiteran: "imperialismo", "mito", "mujer", "recepción", ello refleja las preocupaciones y la mirada de la autora sobre cómo y qué investigar. Desde el análisis ideológico de los mensajes de los medios masivos -en tanto reproductores de la ideología dominante-, el rol de las mujeres en el proceso de dominación, a las preocupaciones por la concentrada y extranjerizada estructura económica y social de los medios de comunicación -en los que los trabajos realizados en el marco del CEREN en Chile ocuparon un rol importante-, hasta un tema menos explorado en dicho período que tiene que ver con los análisis en recepción. En un contexto en el cual predominaban los estudios que hacían foco en la instancia de producción en tanto denunciar la dependencia económica y cultural y la reproducción 
de la ideología dominante, el trabajo de Mabel Piccini y Michèle Mattelart (1974) marca uno de los primeros antecedentes en el tema.

Por último, mencionar que en el recorrido aquí realizado por la vasta y notable trayectoria de la autora, encontramos que Michèle Mattelart sigue postulando -al igual que en los inicios de sus trabajos- la necesidad de profundizar en los temas comunicacionales a partir del encuentro entre economía y cultura, es decir, desde el reconocimiento de la desigualdad y la diferencia. De allí que el reconocimiento de sus aportes resultan indispensables en un campo comunicacional como el actual que se encuentra tensionado entre la fragmentación y la dispersión temática y metodológica, la consolidación académica y la burocratización de las prácticas.

\section{Referencias}

Aguirre Alvis, J. L. (1997). La investigación para democratizar la comunicación: los aportes de Luis Ramiro Beltrán. Revista Ciencia y Cultura. Pp. 77-93. Ang, I. (1982). Watching Dallas: Soap Opera and the Melodramatic Imagination. Londres, Gran Bretaña: Routledge.

Castro, C. (2008). José Marques de Melo: un investigador joven. Revista Chasqui, $\mathrm{n}^{\circ}$ 104. Pp. 4-9.

Crovi Druetta, D. (2004). Aportes latinoamericanos al los estudios de comunicación. En Martell (coord.) Hacia la construcción de una ciencia de la comunicación en México. Ejercicio reflexivo 1979-2004. México: Asociación Mexicana de Investigadores de la Comunicación. Pp.83-99.

Esteinou Madrid, J. (2002). El Mattelart olvidado. Revista Oficios terrestres, $\mathrm{n}^{\mathrm{o}}$ 9, La Plata, Argentina.

Esteinou Madrid, J. (2012). El impulso de Antonio Pasquali al desarrollo de la ciencia y de la comunicación en América Latina. Revista Derecho a comunicar, $\mathrm{n}^{\circ} 6$.

Fuentes Navarro, R. (1992). Un campo cargado de futuro: el estudio de la comunicación en América Latina. Ciudad de México, México: CONEICC.

Mattelart, A. (2013). Por una mirada-mundo. Conversaciones con Michel Sénécal. Temuco, Chile: Ediciones Universidad de la Frontera. 
Mattelart, M. (1976) [1970]. El nivel mítico de la prensa seudo-amorosa. En Armand Mattelart, Mabel Piccini y Michèle Mattelart (eds.). Los medios de comunicación de masas. La ideología de la prensa liberal en Chile. Buenos Aires: Cid Editor. 220-283. Primera edición en Cuadernos de la Realidad Nacional, 3 .

Mattelart, M. (1971). Apuntes sobre lo moderno: una manera de leer el magazine. Cuadernos de la Realidad Nacional, 9. Pp. 156-177.

Mattelart, M. (1975). Chile: The Feminine When Bourgeois Women Side of the Coup or Take to the Streets. En NACLA Report on the Americas, 9:6. Pp. 14-25.

Mattelart, M. (1977). La cultura de la opresión femenina. Ciudad de México, México: Ediciones Era.

Mattelart, M. (1982). Mujeres e industrias culturales. Barcelona, España: Anagrama.

Mattelart, M. (1986). Women, Media, Crisis. Femininity and Disorder. Londres, Inglaterra: Comedia/Methuen.

Mattelart, M. (2004). Género, Tecnología e Identidad. En Agustín García Matilla y Tiscar Lara Padilla (Coords.) Convergencia Multimedia y Alfobetización Digital. Madrid: Facultad de Ciencias de la Información, Universidad Complutense.

Mattelart, M. (2007). Mujeres y medios. Memorias de un pensamiento crítico. En María José Sánchez Leyva y Alicia Reigada Olaizola, Crítica feminista y comunicación. Sevilla, España: Comunicación Social. Pp. 29-55.

Mattelart, M. (2014). Género, comunicación e investigación desarrollada por mujeres. Revista de la Asociación Española de Investigación de la Comunicación, (1) 2. Pp. 1-5.

Mattelart, M. y Mattelart, A. (1968). La mujer chilena en una nueva sociedad. Un estudio exploratorio acerca de la situación e imagen de la mujer en Chile. Santiago de Chile, Chile: Editorial del Pacífico.

Mattelart, M. y Mattelart, A. (1972). Ruptura y continuidad en la Comunicación: puntos para una polémica. Cuadernos de la Realidad Nacional, 12. Pp. 100143.

Mattelart, M. y Mattelart, A. (1987). El carnaval de las imágenes. La Ficción brasileña. Madrid, España: Akal.

Mattelart, M. y Mattelart, A. (1987). Pensar sobre los medios. Comunicación y crítica social. Madrid, España: Fundesco.

Mattelart, M. y Mattelart, A. (1997). Historias de las teorías de la comunicación. Barcelona, España: Paidós. 
Mattelart, M. y Piccini, M. (1973). La prensa burguesa, ¿no será más que un tigre de papel? Los medios de comunicación de la oposición durante la crisis de octubre de 1972. Cuadernos de la Realidad Nacional, 16. Pp. 250-262.

Mattelart, M. y Piccini, M. (1974). La televisión y los sectores populares. Revista Comunicación y cultura, $\mathrm{N}^{\circ}$ 2. Pp. 3-75

Marroquín, A. (2015). La categoría de lo popular-masivo en el pensamiento de Jesús Martín Barbero (Tesis de doctorado). Universidad Centroamericana José Simeón Cañas, Antiguo Cuscatlán, El Salvador. Recuperado de https:// www.academia.edu/12253841/La_categor\%C3\%ADa_de_lo_popular-masivo_en_el_pensamiento_de_Jes\%C3\%BAs_Mart\%C3\%ADn_Barbero

Rincón, O. (Eds.). (2018). Homenaje a los 30 años de los medios a las mediaciones. Bogotá, Colombia: Fescomunicación.

Sánchez Narvate, R. E. y Komissarov, S. (2019). Antonio Pasquali y la escuela de Frankfurt. Lecturas y apropiaciones (1966-1970). Revista Chasqui. Pp. 257-274.

Schramm, W. (1965). Desarrollo de la comunicación y desarrollo económico. San José, Costa Rica: Instituto Interamericano de Ciencias Agrícolas de la OEA.

Solís Leree, B. (2015). Comunicación: memorias de un campo. Entrevistas de Mario Kaplún a los padres fundadores. Ciudad de México, México: Tintable.

Zarowsky, M. (2013). Del laboratorio chileno a comunicación-mundo. Un itinerario intelectual de Armand Mattelart. Buenos Aires, Argentina: Biblos.

Zarowsky, M. (2016). De Los Libros a Comunicación y Cultura. Praxis editorialista y proyecto intelectual en el itinerario de Héctor Schmucler. Revista $L a$ Trama de la Comunicación, vol. 20, núm. 1. Pp. 217-233. 